\title{
INTRAOCULAR DEPOSITION OF METALLIC FRAGMENTS DURING PHACOEMULSIFICATION: POSSIBLE CAUSES AND EFFECTS
}

\author{
C. M. DUNBAR ${ }^{1,2}$, R. R. GOBLE ${ }^{2}$, D. W. GREGORY ${ }^{3}$ and W. C. CHURCH $^{1}$ \\ Aberdeen
}

\begin{abstract}
SUMMARY
We undertook a prospective slit lamp examination of 56 eyes which had undergone routine phacoemulsification, in order to determine the incidence of metallic intraocular foreign bodies. Characteristic small reflective particles were noted in $86 \%$, with a mean of 5.1 particles per affected eye. No accompanying clinical problems were seen. The used phacoemulsification needles were examined with colour photography and scanning electron microscopy. A characteristic pattern of wear was observed, corresponding to an area under the plastic irrigating sleeve rather than at the tip. This suggests cavitation erosion rather than instrument contacts as the cause. Titanium alloy contains $6 \%$ aluminium, $4 \%$ vanadium and $0.25 \%$ iron. All its constituents may corrode and leach from the surface of the metal when in contact with body fluids and have been implicated in numerous adverse biological processes.
\end{abstract}

The use of phacoemulsification in cataract surgery is increasing in the United Kingdom. The postoperative finding of intraocular metal particles has long been recognised, such particles having been considered inert. ${ }^{1,2}$ We attempted to examine and quantify this phenomenon, in the light of recent interest in 'metallosis' and the bioreactivity of titanium alloy. ${ }^{3-8}$

\section{PATIENTS AND METHODS}

Clinical Study

Fifty-four consecutive phacoemulsification patients (56 eyes) were studied. The phacoemulsification

From: ${ }^{1}$ Department of Ophthalmology, Aberdeen Royal Infirmary, Aberdeen; ${ }^{2}$ Paybody Eye Unit, Coventry and Warwickshire Hospital, Coventry; ${ }^{3}$ Forester Hill Electron Microscopy Unit, Department of Medical Microbiology, Medical School Buildings, Forester Hill, Aberdeen, UK.

Correspondence to: Mr C. M. Dunbar, FRCOphth, FRCS, Paybody Eye Unit, Coventry and Warwickshire Hospital, Stoney Stanton Road, Coventry CV1 4FH, UK. equipment contained a Venturi pump with two piezo-electric crystals operating at $28 \mathrm{kHz}$. The diameter of the needle barrel and the width of the phacoemulsification tunnel were $1 \mathrm{~mm}$ and $3.2 \mathrm{~mm}$ respectively.

All patients were examined within 2 weeks of surgery by slit lamp biomicroscopy. Using maximum illumination and magnification, the iris stroma was examined with an angled beam $\left(45^{\circ}\right)$ directed first from the right and then the left. The patient's eye was examined in the primary position and then in upgaze and in downgaze. Particles often glinted when illuminated from one direction only. The number and position of particles were recorded by a single observer (C.M.D.).

\section{Study of Phacoemulsification Needles}

Twelve phacoemulsification needles were examined under the operating microscope and the pattern of wear recorded by colour photography. One new and four used needles were further examined using a Jeol JSM-35CF scanning electron microscope operating at $12 \mathrm{kV}$.

\section{RESULTS}

\section{Clinical Study}

Fifty-six eyes of 54 patients were studied; average patient age was 73.4 years and the male to female ratio was 17 to 37 . All operations were performed at Aberdeen Royal Infirmary by one of four consultants.

Metallic particles were noted in 48 eyes (86\%). The number per eye ranged from 1 to 103 with a mean of 5.1. Only the largest reflected sufficient light to appear on a slit lamp photograph (Fig. 1). Many appeared no larger than a white blood cell. Particles appeared to be randomly distributed over the iris stroma, often within crypts. No accompanying clinical problems were seen. Under the reduced 


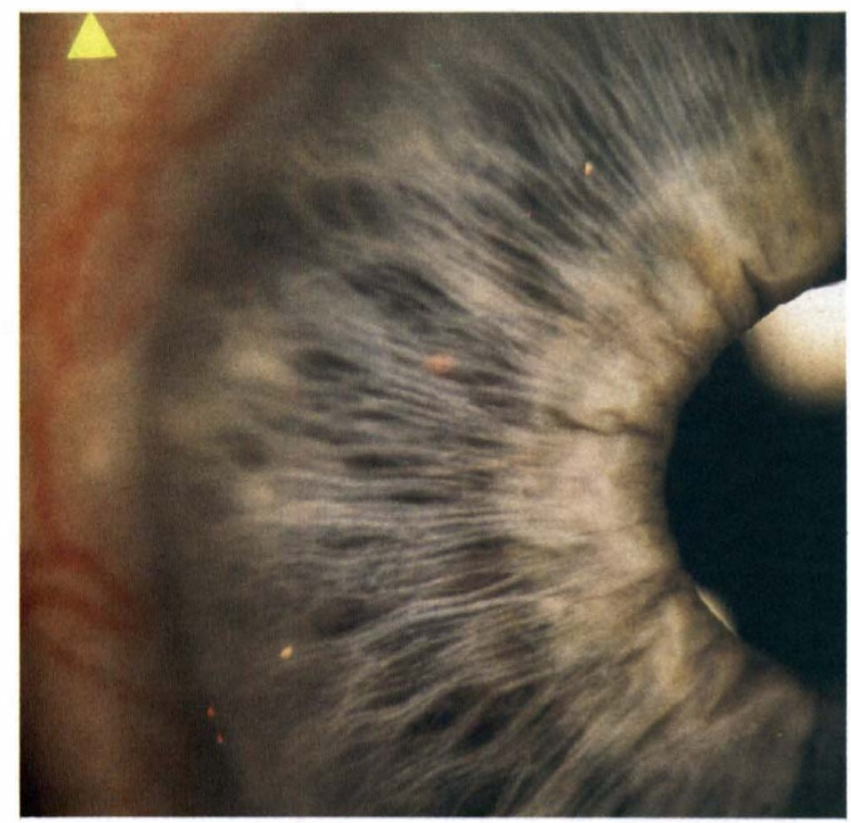

Fig. 1. Two large metallic particles on the iris stroma.

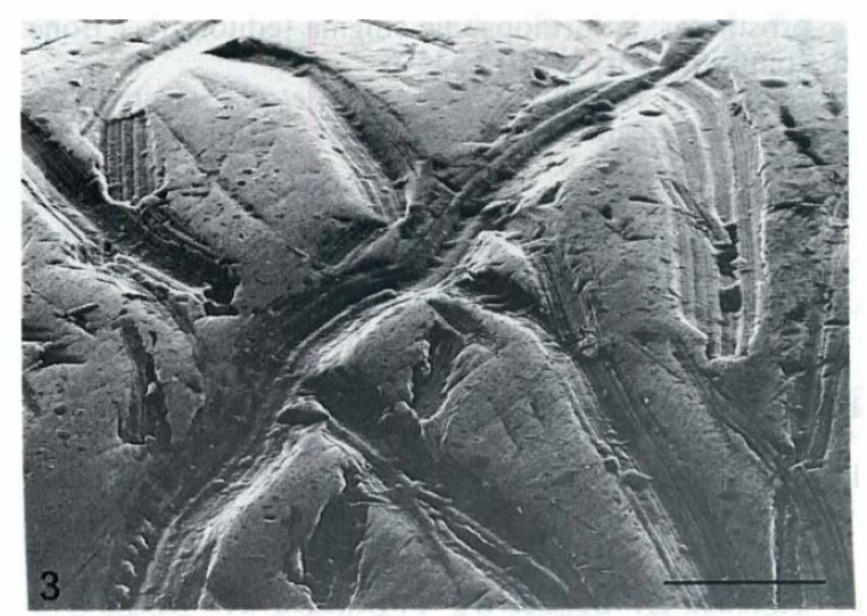

Fig. 3. Electron micrograph detailing erosion marks on a used needle. Scale bar represents $30 \mu \mathrm{m}$.

illumination of gonioscopy, no particles were demonstrated in the drainage angle (5 patients). We did not include particles within the corneal stroma of the phacoemulsification tunnel as these were not strictly intraocular.

\section{Study of Phacoemulsification Needles}

New needles were compared with those used between 1 and 10 times. Fig. 2 illustrates the typical distribution of wear on a used needle. The pattern was apparent even after a single use. There appeared to be relatively little wear at the exposed tips of the needles.

Scanning electron microscopy (SEM) revealed numerous linear markings on the mid-section of the barrel of the used needles (Fig. 3). The new needle showed smaller machining marks (Fig. 4).

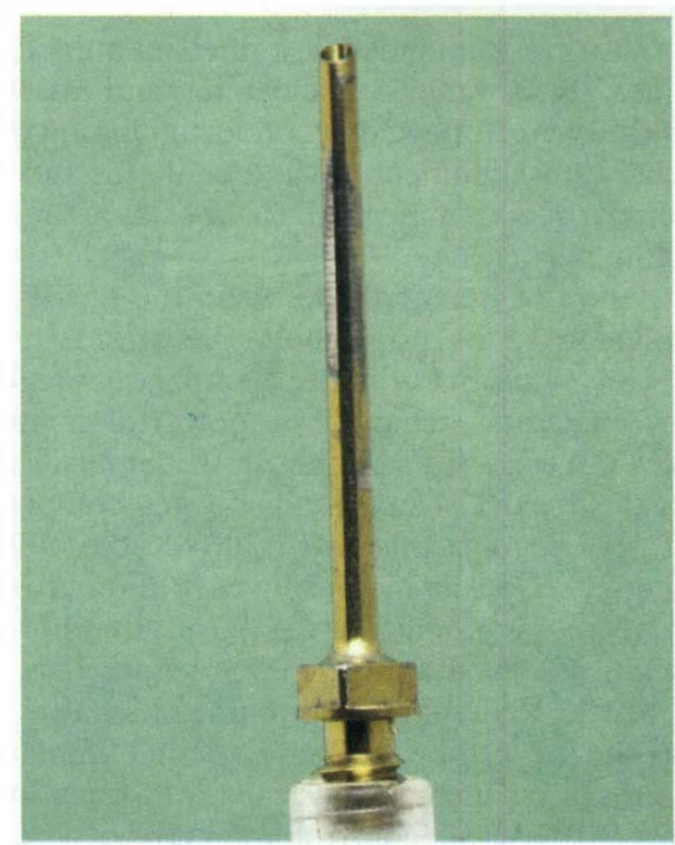

Fig. 2. Used phacoemulsification needle showing loss of gold-coloured surface coating at its mid-section.

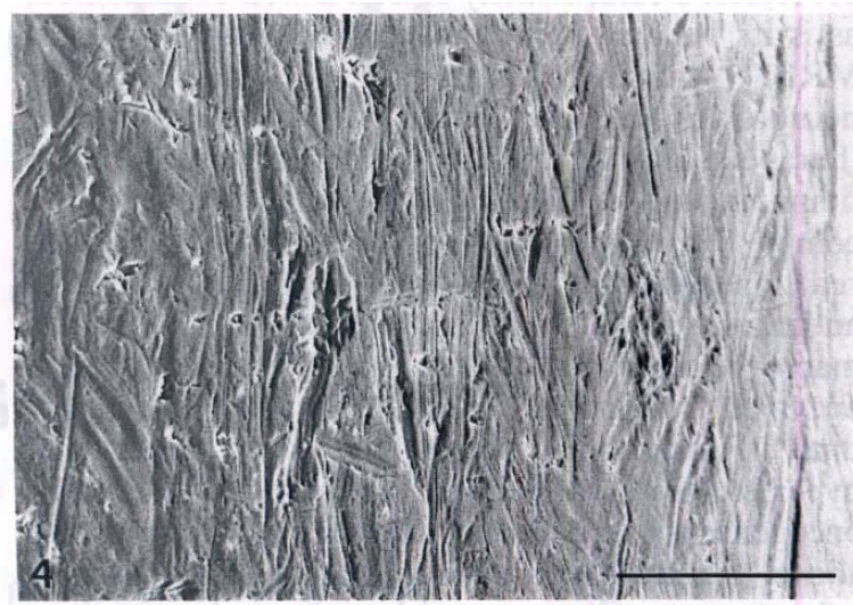

Fig. 4. Electron micrograph of an equivalent section of a new needle. Scale bar represents $30 \mu \mathrm{m}$.

\section{DISCUSSION}

Post-operative intraocular metallic foreign bodies have been sporadically reported after phacoemulsification. ${ }^{1,2}$ Our study suggests that it is a common occurrence. The examination of used phacoemulsification needles revealed erosion of the outer surface; any particles eroded from this region would tend to be washed into the eye by the irrigating fluid. No examination of the other parts of the phacoemulsification handpiece was carried out, and other sources of particles were therefore not excluded.

A characteristic pattern of erosive marks midway along the barrel was observed clinically and with SEM, corresponding to an area protected by an outer plastic sleeve whilst the instrument is in use. This is inconsistent with inadvertent instrument contacts as a cause. ${ }^{2}$ None of the needles had been used more 
often than recommended by the manufacturer's guidelines. Recommended cleaning and assembly procedures were followed, as undertightening of the needle and misalignment of the needle tip and nose cone in particular may lead to liberation of ironcontaining particles. ${ }^{2}$

The region of maximum wear on the needle also corresponded to its position in the scleral/corneal tunnel whilst in use. At the needle tip, liquefaction of the lens nucleus is achieved by powerful cavitation erosion forces. Within the phacoemulsification tunnel, the plastic sleeve tends to get compressed against the needle; this might affect the flow of irrigating fluid, locally increasing cavitation erosion. ${ }^{9}$

The needle is composed of $90 \%$ titanium, $6 \%$ aluminium, $4 \%$ vanadium and $0.25 \%$ iron. This alloy is less brittle than pure titanium and is also used extensively for orthopaedic and dental implants. ${ }^{10}$ Recent research increasingly calls into question its inertness. ${ }^{3-8,12}$ All its constituents may corrode and leach from the surface of the alloy when in contact with body fluids and participate freely in biological processes. Ocular toxicity of iron is well documented, as is its behaviour in a magnetic fluid (relevant to MRI). ${ }^{2}$ Aluminium salts are recognised to be neurotoxic, ${ }^{5}$ and vanadium salts have been used therapeutically in spirochaetal infections. ${ }^{6}$ Even titanium, one of the most inert of metals, is not completely so. In block form it produces little tissue reaction, although leaching has been documented in an animal model. ${ }^{11}$ In particulate form it attracts macrophages which react by releasing lysosomal enzymes, collagenase, interleukins and prostaglandins. ${ }^{6}$ Furthermore, there have been reports of hypersensitivity to titanium and a possible role in oncogenesis has been postulated. $5,12,13$ Despite the above, we are at present unaware of any toxic or inflammatory effects caused by intraocular titanium alloy.

This study indicates that residual metallic particles after phacoemulsification are more common than previously recognised. We speculate that further particles, too small to be seen at the slip lamp, may also be present. We believe the outer surface of the needle to be one source of particles. It would seem desirable to prevent this occurrence, as titanium alloy is not completely inert.

Key words: Cataract extraction - complications, Cavitation erosion, Intraocular foreign body, Metallosis, Phacoemulsification, Titanium alloy.

\section{REFERENCES}

1. Emery JM, Little JH. Phacoemulsification and aspiration of cataracts. St Louis: CV Mosby, 1979:29.

2. Metal fragments shed by Storz Premiere Phacoemulsification units. Health Devices 1993;22:304-6.

3. Williams DF. Titanium: epitome of biocompatibility or cause for concern? J Bone Joint Surg [Br] 1994;76: 348-9.

4. Moran CA, Mullick FG, Ishak KG, et al. Identification of titanium in human tissues: probable role in pathologic processes. Hum Pathol 1991;22:450-4.

5. Black J. Does corrosion matter? [editorial] J Bone Joint Surg [Br] 1988;70:517-20.

6. Scales JT. Black staining around titanium alloy prostheses: an orthopaedic enigma [editorial]. J Bone Joint Surg [Br] 1991;73:534-6.

7. Lalor PA, Revell PA, Gray AB, et al. Sensitivity to titanium: a cause of implant failure? J Bone Joint Surg [Br] 1991;73:25-8.

8. Jacobs JJ, Skipor AK, Black J, et al. Release and excretion of metals in patients who have a total hip replacement component made of titanium-base alloy. J Bone Joint Surg [Am] 1991;73:1475-86.

9. Horger OJ, editor. Metals engineering design. 2nd ed. New York: McGraw-Hill, 1965:390-2.

10. Simons EN. A dictionary of alloys. London: Frederick Muller, 1969:162-3.

11. Ferguson AB, Akahoshi Y, Laing PG, et al. Characteristics of trace ions released from embedded metal implants in the rabbit. J Bone Joint Surg [Am] 1962;44:323-36.

12. Abdallah HI, Balsara RK, O'Riordan AC. Pacemaker contact sensitivity: clinical recognition and management [review]. Ann Thoracic Surg 1994;57:1017-8.

13. Gillespie WI, Frampton CMA, Henderson RI, et al. The incidence of cancer following total hip replacement. J Bone Joint Surg [Br] 1988;70:539-42. 